\title{
Comparison of Swedish and Norwegian Use of Cone-Beam Computed Tomography: a Questionnaire Study
}

\author{
Jerker Edén Strindberg ${ }^{1,2,}$ Caroline $\mathrm{Hol}^{3}$, Gerald Torgersen ${ }^{4}$, Anne Møystad ${ }^{4}$, Mats Nilsson ${ }^{5,6}$, Karin \\ Näsström ${ }^{1}$, Kristina Hellén-Halme ${ }^{6}$ \\ ${ }^{1}$ Division of Image and Functional Odontology, Department of Dental Medicine, Karolinska Institute, Stockholm, Sweden. \\ ${ }^{2}$ Department of Hospital Physics, Danderyd Hospital, Stockholm, Sweden. \\ ${ }^{3}$ Oral Health Centre of Expertise in Southern Norway, Arendal, Norway. \\ ${ }^{4}$ Department of Maxillofacial Radiology, Institute of Clinical Odontology, Faculty of Dentistry, University of Oslo, Oslo, \\ Norway. \\ ${ }_{5}^{5}$ Department of Radiation Physics, Skåne University Hospital, Malmö, Sweden. \\ ${ }^{6}$ Department of Oral and Maxillofacial Radiology, Faculty of Odontology, Malmö University, Malmö, Sweden.
}

\author{
Corresponding Author: \\ Karin Näsström \\ Division of Image and Functional Odontology \\ Department of Dental Medicine, Karolinska Institutet \\ S-141 04 Huddinge \\ Sweden \\ Phone: +46852488150 \\ Fax: +4687795301 \\ E-mail: karin.nasstrom@ki.se
}

\begin{abstract}
Objectives: Cone-beam computed tomography in dentistry can be used in some countries by other dentists than specialists in radiology. The frequency of buying cone-beam computed tomography to examine patients is rapidly growing, thus knowledge of how to use it is very important. The aim was to compare the outcome of an investigation on the use of cone-beam computed tomography in Sweden with a previous Norwegian study, regarding specifically technical aspects.

Material and Methods: The questionnaire contained 45 questions, including 35 comparable questions to Norwegian clinics one year previous. Results were based on inter-comparison of the outcome from each of the two questionnaire studies.

Results: Responses rate was $71 \%$ in Sweden. There, most of cone-beam computed tomography (CBCT) examinations performed by dental nurses, while in Norway by specialists. More than two-thirds of the CBCT units had a scout image function, regularly used in both Sweden (79\%) and Norway (75\%). In Sweden 4\% and in Norway $41 \%$ of the respondents did not wait for the report from the radiographic specialist before initiating treatment.

Conclusions: The bilateral comparison showed an overall similarity between the two countries. The survey gave explicit and important knowledge of the need for education and training of the whole team, since radiation dose to the patient could vary a lot for the same kind of radiographic examination. It is essential to establish quality assurance protocols with defined responsibilities in the team in order to maintain high diagnostic accuracy for all examinations when using cone-beam computed tomography for patient examinations.
\end{abstract}

Keywords: cone-beam computed tomography; dentistry; health care quality assurance; questionnaire; workflow.

Accepted for publication: 23 December 2015

To cite this article:

Strindberg JE, Hol C, Torgersen G, Møystad A, Nilsson M, Näsström K, Hellén-Halme K.

Comparison of Swedish and Norwegian Use of Cone-Beam Computed Tomography: a Questionnaire Study

J Oral Maxillofac Res 2015;6(4):e2

URL: http://www.ejomr.org/JOMR/archives/2015/4/e2/v6n4e2.pdf

doi: $10.5037 /$ jomr.2015.6402 


\section{INTRODUCTION}

Cone-beam computed tomography (CBCT) has rapidly become a huge success in the dental radiographic world. The first CBCT was installed in Sweden in 2002, and in 2007 the first device was installed in Norway. A multinational research project, SEDENTEXCT, supported by the Seventh Framework Programme of the European Atomic Energy Community (Euratom) published guidelines for the use of CBCT in 2012 [1]. In Europe, not all countries have incorporated these guidelines into their national regulations. As a result, in countries like Sweden, where the EU guidelines have not been incorporated yet, the general radiation protection regulations and regulations regarding for specialist radiographic equipment and medical $\mathrm{CT}$ should be applied in to the use of CBCT. According to the regulations in Sweden and in Norway, all CBCT units have to be registered and supervised by a medical physicist responsible for performing quality assurance (QA), including dose measurements [1, 2$]$. A medical or a dento-maxillofacial radiologist has to be responsible for the clinical use of the CBCT unit, including interpretation of the results from the examinations. In Norway, the radiologist may delegate CBCT image interpretation to another competent dentist when imaging the dento-alveolar region with scan volumes of $8 \times 8 \mathrm{~cm}$ or smaller. The Norwegian Radiation Protection Authority (NRPA) published guidelines for the use of CBCT in dental practices in 2010, and excluding the mandatory demand of a responsible radiologist and physicist, the guidelines are adjusted to, though not identical to the "Basic principles" in the EU guidelines described by the SEDENTEXCT project.

Sweden and Norway are similar countries in many aspects. Both countries have high gross domestic products and governmental spending per capital, and low population densities [3]. The population of Sweden is approximately twice that of Norway (9.6 and 5.1 million). According to Swedish statistics from 2012 and Norway in 2014 [4], the number of inhabitants per active dentist were almost identical (1.235 in Sweden and 1.153 in Norway), as were the number inhabitants per active specialist (10.842 in Sweden 2007 and 11.161 in Norway 2008) [ [ ] In both countries there were slightly more female dentists (54 and 52\% respectively) [4]. However, one major difference was the number of general practice dentists in private care, $46 \%$ in Sweden whilst $69 \%$ in Norway [4]. Given all these statistics the amount of registered CBCT units in each country
(75 in Sweden in December 2013 and 39 in Norway December 2012) were comparable in relation to both population and numbers of dentists/specialists.

In December 2012, a questionnaire was sent with a wide range of questions, to all $\mathrm{CBCT}$ clinics registered nationally with the NRPA in Norway. Many questions focused on how CBCT was used by most dentists [6]. The study focused on clinically related questions, including the actual workflow with the CBCT. Due to the relatively early use of CBCT in Sweden without explicit regulations, it might be reasonable to expect a difference in the use of CBCT compared to Norway. In addition, there should also be many similarities according to the analogy of the two countries, for example both countries have an acknowledged speciality in dental and maxillofacial radiology, and to engage a medical physicist is mandatory for the use of CBCT in both countries.

Previous studies in Turkey have concluded that there is a difference in knowledge about CBCT technique among the dental students, and that digital techniques and specific knowledge about CBCT and its usefulness in the clinic should be highlighted $[\underline{7}, \underline{8}]$. Today most dentists and dental staff in Norway and Sweden are familiar with the use of service agreements, support and back-up routines using intraoral digital radiography. The use of technical parameters to improve image quality and reduce image dose, such as tube current $(\mathrm{mA})$ and tube voltage $(\mathrm{kV})$, support devices for patient positioning, field of view (FOV) and scout images, however, is a new challenge for the dental staff with regard to CBCT examinations. To our knowledge, there is no literature regarding dental staff and their use of the more advanced technical parameters used with CBCT. Thus, the aim of this study was to compare the outcome of an investigation in the use of conebeam computed tomography in Sweden with previous responses made in Norway, with regard specifically to technical issues, not previously reported.

\section{MATERIAL AND METHODS Bilateral comparison}

In November 2013, 76 questionnaire forms were sent to all dental clinics with CBCT equipment, registered by the Swedish Radiation Safety Authority (SRSA, www.ssm.se) in September 2013, and another six to additional CBCT clinics known by the authors, but not registered by SRSA by the time the copy of the registry was achieved. One of the clinics that was added by authors overlapped with one registered by SRSA but had been renamed and was thus excluded. 
Furthermore, five respondents reported that their CBCT units were discontinued or scrapped, and another clinic was yet to install their CBCT machine. These respondents were also excluded, which meant that the response rate was calculated based on the remaining 75 questionnaires. The Swedish questionnaire was sent to the contact person registered by SRSA or to the clinic. A cover letter accompanying the Swedish questionnaire informed the respondents that their answers would be treated anonymously. A coded and stamped envelope was supplied for the return of the questionnaire, and two reminders were sent out. The questionnaire contained a total of 45 questions, including 35 identical or comparable questions to the Norwegian questionnaire, which had been sent to the Norwegian clinics one year earlier []. The present study was based on inter-comparison of the results of the Swedish questionnaire and the acquired data from the Norwegian questionnaire, focusing on questions related to technical issues of the CBCT. In the previous study [6], an analysis was performed of the clinical approach to using CBCT.

The questionnaire comprised questions regarding the characteristics of the respondents, such as gender and age, as well as the formal competence of the staff in the clinic, the radiographic equipment and its use. The questionnaire also included a question about perceived radiation dose in CBCT, as well as about the most common clinical indications for using CBCT, QA program, image processing, image quality, installation, radiation protection and technical support. The full questionnaire can be obtained from the corresponding author.

\section{Statistical analysis}

We used pairwise analysis between Sweden and Norway. Data in both the Swedish and the Norwegian questionnaires were imported into Microsoft Excel 2013 (Microsoft Corporation, Redmond, WA, USA).

Pivot tables were used to sort, count and relate the parameters of the different questions. Some parameters were also checked for correlation by statistical hypothesis testing. The hypothesis that one numerical parameter was a function of another was evaluated by calculating the coefficient of determination, $R^{2}$, which indicated how well data was consistent with a statistical model. A value close to 1 indicated that the model was consistent. Correlations between numerical and non-numerical parameters were tested with one-way analysis of variance (ANOVA) which was automated in Microsoft Excel 2013 and provided a measure of significance.
The respondents were asked to rank the commonness of each indication with a commonness rank, $R$, ranging from 1 to 5 . In the Swedish questionnaire a commonness rank of 1 demonstrated that the indication was the most common, whereas 5 showed the most common rank in the Norwegian study. For statistical reasons the Swedish commonness factors were reversed so that they corresponded to the Norwegian and indications, which were not ranked by a respondent, were treated as $R=0$.

To assess the frequency of the indications, rather than just the most common indication, the mean value of the commonness rank, $\bar{X}$, was calculated for each indication according to the following formula of weighted arithmetic mean value, where $X_{R}$ was the number of respondents who had stated rank $R$ for a certain indication, and $N$ the total number of respondents:

$$
\bar{X}=\frac{\sum_{R=0}^{5} X_{R} \cdot R}{N}
$$

\section{RESULTS}

Responses from the Swedish questionnaire were 53 out of $75(71 \%)$, and were received from 50 clinics, including hospital and university clinics. In the Norwegian study, 29 out of 39 (74\%) responded the questionnaire [6]. Due to the fact that two Swedish clinics owned more than one CBCT unit, these questionnaires represented the same clinic but different CBCT units, and thus were answered identically except for the technical details of the equipment.

\section{Respondents}

The respondents were almost exclusively male in Norway (93\%) [6], whereas only $65 \%$ of the Swedish respondents were male. The age distribution of the respondents differed between the countries (Table 1). In Sweden, $50 \%$ of the respondents were 55 years or older, compared to $28 \%$ in Norway. In Norway, $83 \%$ of the clinics had at least one dental specialist, other than oral and maxillofacial radiologist,

Table 1. The respondents age distribution in percent

\begin{tabular}{c|c|c}
\hline Respondents age & Sweden & Norway \\
\hline $24-34$ & $6 \%$ & $10 \%$ \\
\hline $35-44$ & $32 \%$ & $24 \%$ \\
\hline $45-54$ & $12 \%$ & $38 \%$ \\
\hline $55-64$ & $40 \%$ & $28 \%$ \\
\hline $65+$ & $10 \%$ & $0 \%$ \\
\hline
\end{tabular}


in addition to one radiologist required by regulations, compared to only $54 \%$ of the Swedish clinics. On the other hand, $9 \%$ of the Swedish clinics had more than one radiologist, whereas none of the Norwegian respondents reported more than one radiologist in their clinics.

\section{Equipment}

The CBCT units in Sweden came from ten different manufacturers, in Norway seven, all of which were represented in Sweden. In Sweden, J. Morita Corporation (Fushimi-ku, Kyoto, Japan) was the dominating manufacturer (40\%), whilst in Norway, Sirona unit (Sirona Dental Systems, Inc. Long Island City, NY, USA) (31\%) was most commonly represented. The CBCT units were installed during the last two decades, gradually increasing with a clear peak in purchase at the beginning of this decade (Figure 1). About half of the clinics needed to rebuild before installation of CBCT (45\% Norway, 54\% Sweden) and the most common issue was to expand the radiation protection.

\section{Technical issues}

Most clinics had service agreements for their equipment (Sweden 88\%, Norway 97\%). The service agreements included upgrades of hardware (Sweden $63 \%$, Norway 55\%), firmware (Sweden 65\%, Norway $67 \%$ ) and software (Sweden $88 \%$, Norway 96\%), as well as technical support (Sweden 93\%, Norway 96\%). Some $(7-29 \%)$ respondents in both countries did not know if all of these options were included in the service agreement. Almost every respondent claimed to be satisfied with the support and none claimed to be dissatisfied. In both countries, more than $96 \%$ of the respondents reported to performing regular back-ups.

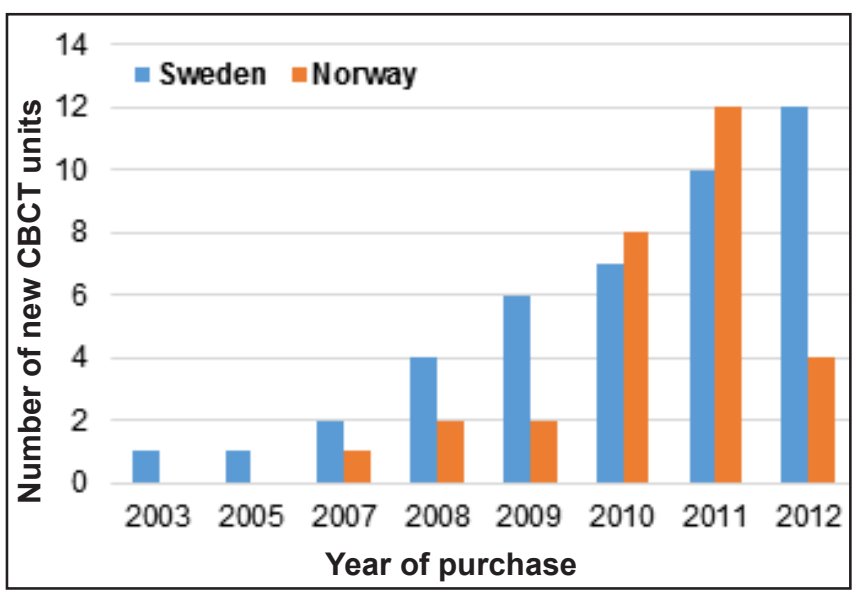

Figure 1. Distribution of purchase year for cone-beam computed tomography (CBCT) in Sweden and Norway.

\section{Cone-beam computed tomography scanning}

In $60 \%$ of the Swedish clinics, the same person performed all CBCT examinations compared to $86 \%$ in Norway. In Sweden, most examinations were performed by dental nurses in contrast to Norway, where they were performed by specialists. In both countries, the second most common performers of CBCT examinations were general practice dentists.

In Sweden two respondents had CBCT units with supine patient positioning. In both countries patients in the standing position was most common (Table 2). The use of patient head support was generally more common in Norway. At least three different support devises were used by $58 \%$ of the Swedish respondents compared to $83 \%$ of the Norwegian respondents. Frontal head and chin support were common, whereas neck support was not commonly used in any of the countries (Table 3).

In both countries, more than two-thirds of the CBCT units had a scout image function, which was regularly used (79\% in Sweden and 75\% in Norway).

Among examination parameters, "Field of View" (FOV) was by far the most common parameter to modify. Other common parameters were size of voxel, tube current and tube voltage (Table 4).

Table 2. Patient positioning in the cone-beam computed tomography unit

\begin{tabular}{c|c|c}
\hline Patient positioning & Sweden & Norway \\
\hline Supine & $4 \%$ & $0 \%$ \\
\hline Sitting & $41 \%$ & $31 \%$ \\
\hline Standing & $55 \%$ & $69 \%$ \\
\hline
\end{tabular}

Table 3. Frequency of respondents using patient support

\begin{tabular}{l|c|c}
\hline \multicolumn{1}{c|}{ Patient support } & Sweden & Norway \\
\hline Chin support & $78 \%$ & $90 \%$ \\
\hline Bite stick & $40 \%$ & $48 \%$ \\
\hline Side support/temporal support & $52 \%$ & $62 \%$ \\
\hline Frontal head support & $38 \%$ & $55 \%$ \\
\hline Forehead band & $34 \%$ & $59 \%$ \\
\hline Neck support & $22 \%$ & $24 \%$ \\
\hline Neck band & $6 \%$ & $10 \%$ \\
\hline
\end{tabular}

Table 4. Frequency of respondents altering the technical parameters

\begin{tabular}{l|c|c}
\hline Technical parameters & Sweden & Norway \\
\hline Tube current $(\mathrm{mA})$ & $74 \%$ & $76 \%$ \\
\hline Tube voltage $(\mathrm{kV})$ & $74 \%$ & $79 \%$ \\
\hline Exposure time $(\mathrm{s})$ & $46 \%$ & $62 \%$ \\
\hline Voxelsize/image resolution & $68 \%$ & $72 \%$ \\
\hline Field of view (FOV) & $86 \%$ & $97 \%$ \\
\hline Rotation length $\left(^{\circ}\right)$ & $38 \%$ & $14 \%$ \\
\hline Other adjustable parameters & $8 \%$ & $10 \%$ \\
\hline
\end{tabular}




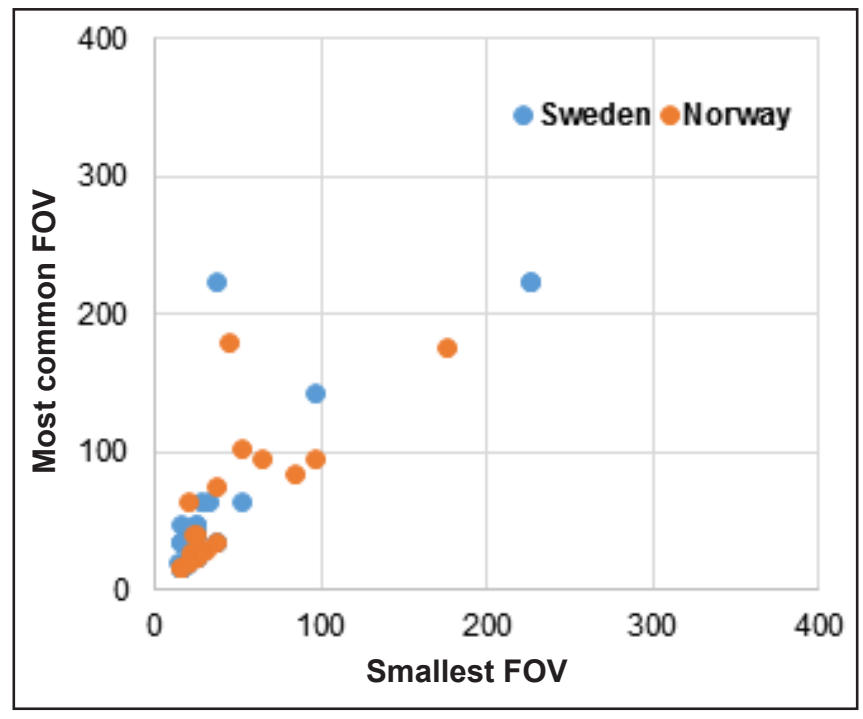

Figure 2. The most commonly used field of view (FOV) as a function of the smallest selectable FOV measured in $\mathrm{cm}^{2}$ as the product of height and diameter of the radiation field in isocenter.

The most common FOV, defined as the product of width and height, was plotted against the smallest FOV (Figure 2). The hypothesis that the smallest FOV was most commonly used would be modelled by a linear graph with slope one in the plot. The hypothesis was tested by calculating the coefficients of determination $\left(\mathrm{R}^{2}\right)$ of the model to the data. The same calculation was made for the most common FOV plotted against the largest FOV (Figure 3) with the hypothesis that the largest FOV was the most commonly used.

The tests supported the hypothesis that the smallest FOV was most commonly used $\left(\mathrm{R}^{2}=0.75\right.$ in Sweden, $\mathrm{R}^{2}=0.7$ in Norway) rather than the largest FOV $\left(\mathrm{R}^{2}=0.41\right.$ in Sweden, $\mathrm{R}^{2}=0.32$ in Norway).

\section{Indications and use of images}

In both countries, the most common indication for performing $\mathrm{CBCT}$ examinations was implant treatment planning (76\% Sweden, 34\% Norway). Figure 4 shows the mean of Rank-ordered indications. Following implant treatment planning the most common indications were impacted teeth, jaw pathology and pain-related problems in both countries. Other indications were only common in few clinics, although $14 \%$ of the Swedish clinics (3\% in Norway) stated that other indications, such as sinus or root anatomy, were the most common. Correlations between most common indication and most commonly used FOV were tested with ANOVA, but no significant correlation was found.

All respondents read the report from the specialist.

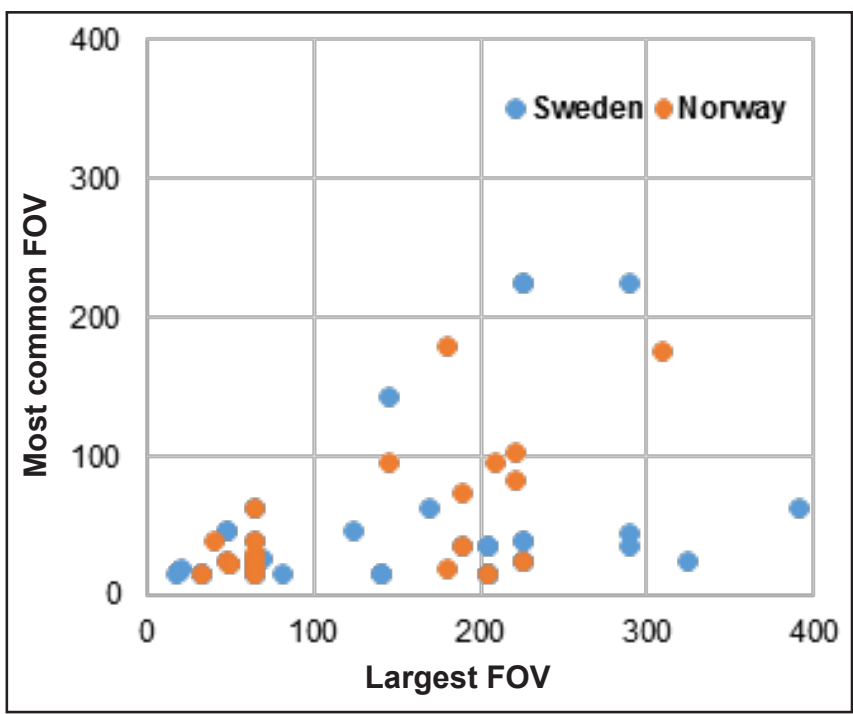

Figure 3. The most commonly used field of view (FOV) as a function of the largest selectable FOV measured in $\mathrm{cm}^{2}$ as the product of height and diameter of the radiation field in isocenter.

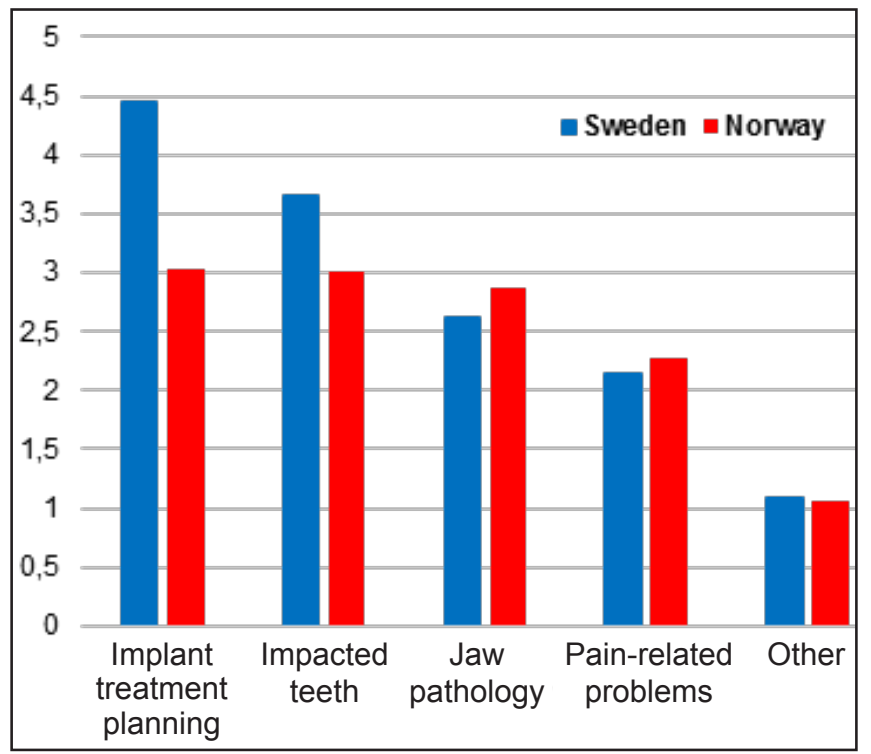

Figure 4. Mean of rank-ordered indications.

A majority of the Swedish respondents also reviewed the images, $96 \%$, while $78 \%$ of the Norwegian respondents evaluated the images. Four percent of the Swedish respondents and $41 \%$ of the Norwegian respondents did not wait for the report before initiating treatment.

Demonstrating the images to the patients was very common in both countries (93\% in Sweden and $85 \%$ in Norway).

\section{Cone-beam computed tomography dose level}

The conception of CBCT dose level, compared to intraoral imaging was similar between the countries, with a tendency towards larger number of periapical images (Table 5). 
Table 5. The frequency of the respondents who estimated the smallest field of view, $4 \times 4 \mathrm{~cm}$, cone-beam computed tomography radiation dose, correlated to the numbers of periapical images

\begin{tabular}{c|c|c}
\hline $\begin{array}{c}\text { Number of } \\
\text { intraoral images }\end{array}$ & Sweden & Norway \\
\hline$<5$ & $8 \%$ & $7 \%$ \\
\hline $5-10$ & $12 \%$ & $19 \%$ \\
\hline $11-20$ & $27 \%$ & $37 \%$ \\
\hline $21-40$ & $31 \%$ & $26 \%$ \\
\hline$>40$ & $22 \%$ & $11 \%$ \\
\hline
\end{tabular}

Correlations between conception of CBCT dose levels and other parameters were tested with ANOVA, but no significant correlation was found. The parameters tested were age, sex and education of the respondent, education of the operator, CBCT manufacturer and trade name, variable exposure parameters and year of CBCT purchase as well as most common indications, frequency of examinations and most common FOV.

\section{DISCUSSION}

The first and principal purpose of the current study was to compare the use of CBCT devices between the two countries, Sweden and Norway. Furthermore the use of the devices within each country was registered, as well as the technical parameters related to the use of the CBCT. The similarities in CBCT use were obvious in terms of how the respondents worked according to national regulations that exist, even though in Sweden one must interpret the rules of CBCT in the context of medical X-ray machines. However, the differences when the regulations were applied in practice might be of interest to notice. These differences could be explained by various interpretations of the regulations due to lack of information and/or knowledge, no clear definition of responsibilities to everyone in the team working with CBCT, and/or no QA program defined, including continuous follow-up courses from both technical and diagnostic aspects. It was not mandatory and there were no rules that prescribed attending radiological courses in any of the countries, although there is the obvious need for knowledge concerning continuous optimization of image quality and to maintain high diagnostic accuracy. Examples of differences are discussed below.

In the Swedish survey, the questionnaire forms were sent to all 76 clinics, registered by the SRSA and to six additional clinics not registered at the time of sending the survey to respondents. The Swedish questionnaire was sent out a year later than the Norwegian questionnaire in a time of rapid increase in the use of CBCT. The response rate of our study was $71 \%$. Due to the fact that there are certain well known difficulties connected with questionnaire surveys, and among them maybe the most important is to get answers from the respondents, a response rate of $70-80 \%$ is considered to be acceptable. Our respond rate corresponded well with previous studies [9-11]. Our questionnaire was sent out as a printed copy, with two reminders, whilst in Norway it was sent both in a digital and analogue form with four reminders, resulting in a response rate of $74 \%$. Surprisingly, there were some difficulties to get response with the questionnaire which was sent digitally. Therefore, in Sweden it was chosen to send the investigation only by postal mail. Another recognized problem with questionnaire surveys is that the actual respondent is not known. In our study the questionnaire was sent to the person registered as owner of the CBCT device, which allowed either the owner or the user, if not the same person, to answer the questions. The respondents answered anonymously. The problem was the same in the Norwegian study and thus the results were comparable [ 6$]$.

The answers received in the Swedish survey represented all kind of clinics, as general dentists, specialists, hospitals and universities. The clinics in Sweden that chose not to answer included all type of clinics and therefore none obvious bias can be detected. However, in the Norwegian survey none of the hospitals or universities responded. The difference in kind of responses from clinics between the countries, might have affected the results of the answers, especially concerning the workflow and questions about indication for CBCT examinations. In the Swedish survey, six answers were registered, where most common indications were examinations of sinuses and root investigations. These answers might indicate that the examinations were performed and interpreted by a specialist clinic in dento-maxillofacial radiology or endodontics. Implant treatment planning, impacted teeth, jaw pathology and pain-related problems were the most common in both countries, as expected.

Another difference at the time of the Norwegian survey was that only dento-maxillofacial radiologists, radiographers and specially trained dentists were allowed to perform the actual CBCT scans and not dental nurses as in Sweden. This might have influenced some of the answers of the surveys, since the education in radiology, both about radiological techniques and diagnostics, was on a higher level in Norway, than for dental nurses in Sweden. Considering the indication for a CBCT examination 
in relation to choosing exposure parameters and FOV, this could be expected to show differences between the countries. One hypothesis could be that larger FOV than necessary would be chosen, to ensure enough volume for interpretation, when knowledge about the radiological technique and image quality optimisation would be expected to be lower. The answers did not result in any statistically significant differences related to the level of education for the study participants between Sweden and Norway.

A notable difference between the countries was the use of patient head support, where the use of at least three different head supports were commonly used in Norway during CBCT exposure, in contrast to Sweden, where only two head supports were generally used. This difference was substantial even when the same models of CBCT were compared.

In a previous study simulation showed that only chin and forehead support were inadequate to prevent risk of head rotations, which can cause clearly visible loss in image quality [12] and the importance of using multiple supports have been advised by the European Academy of Dental and Maxillofacial Radiology (EADMR) [13]. The results in this study could be related to different brand of CBCT machine with enclosed alternative head supports. It is therefore, important to be aware when invest in a new CBCT, the head supports included should be clearly documented.

Another difference was how the respondents handled the report from the specialist in dento-maxillofacial radiology, after the $\mathrm{CBCT}$ examination in relation to start of treatment. In Sweden around ten times more respondents waited for the specialist report before starting treatment than in Norway. This might be explained by the fact that in Norway most of the responsible users were specialists in dentistry, other than in dento-maxillofacial radiology. Far more were general dentists using CBCT in Sweden and thus maybe less experienced in analysing advanced radiological examinations. To our knowledge it remains to be determined, if there would be any changes in treatment, if the dentist had read the report in advance of start of treatment.

In both countries FOV was the most common examination parameter to alter. The smallest available FOV was significantly more commonly used, regardless of the indication. An important fact, worth considering, was that the size of the smallest FOV depended on the CBCT model. The ratio between the CBCT with largest and smallest areas for the smallest selectable FOV was found 16 in Sweden and 11 in Norway. This indicated that the choice of equipment could have had an obvious impact on the radiation dose, which might not be compensated by optimisation of the scanning parameters $[\underline{14}, \underline{15}]$.

In our study it was shown that a scout-image was available on most CBCT devices in order to be able to focus the correct position of volume of interest before exposing the patient. This function was not used in $20-25 \%$ of the examinations, regardless of which country and size of FOV. The consequence of not using this function, amongst others, is that it will increase the risk of re-exposure, due to failure of positioning the volume correctly, and it might be especially difficult when positioning small volumes [1]. This remarkable negligence of using the scoutimage function could thus lead to the risk of a higher dose to the patient, a possible necessity of retaking the volume, or maybe less image quality if accepting sub-optimal images. The scout-image function should be regarded as part of a QA program in every clinic where this function is available on the CBCT device [1]. The two scout-images are acquired using a very low X-ray tube current and short exposure times and will thus contribute only marginally to the total dose to the patient from the whole CBCT examination.

The conception of CBCT dose level, compared to intraoral imaging in both Sweden and Norway, ranged from less than five intraoral exposures to more than 40. This more than eight-fold range had no significant correlation to the $\mathrm{CBCT}$ equipment, $\mathrm{FOV}$, indication or any other reasonable parameter. Considering that several clinics in both countries used the same kind of equipment and FOV, plus the fact that the same indications were the most common, this showed a great need for further education, such as more knowledge on CBCT doses, and elaboration of some standard QA methods. The QA methods could be used for CBCT owners and users, other than those expected from the responsible specialist in radiology or the medical physicist [16].

Previous studies have investigated the dose to the patient in CBCT devices in relation to image quality [17-19]. It is clear that the dose to patients differed a lot and it was difficult to express an adequate dose from the CBCT examination due to the many different parameters that could and are used. Hence, the risk that the dose might be raised, without concomitant benefit for the patient when interpreting the examination, is obvious. These facts, about different possibilities in the use of CBCT, emphasise the importance of knowledge in QA optimisation, in order to work according to the ALARA principle [1]. In this context the relevant question also arises if it is suitable to express dose as effective dose, if the irradiated volume is very small [20-24]. 
This is emphasized by the facts that the tissue types included in the ICRP 103 weight factor table and which are irradiated in a CBCT examination (red bone marrow, parotid gland, oral mucosa, thyroid gland, skin, bone surfaces, brain, extrathoracic tissue and lymph nodes) either have a low weight factor or are irradiated only to a small fraction (or both). The effective dose will therefore be orders of magnitude smaller than the local absorbed dose in the irradiated volume. Furthermore, due to the steep dose gradients around a CBCT volume and variations in human anatomy and placement of the CBCT field of view between individuals, the effective dose will exhibit very large variations between individuals. Any value of effective dose compiled from phantom measurements should therefore be used with great caution, if at all.

A thought that strikes when you add up all the results is that there is a strong need for continuous upgrade of knowledge to everyone in the team working with CBCT, as well as to clarify and define the different roles and responsibilities within the team involved using $\mathrm{CBCT}$ devices.

\section{CONCLUSIONS}

This study compared the use of cone-beam computed tomography for dento-maxillofacial purposes in Sweden and Norway. The bilateral comparison showed an overall similarity between the two countries, probably due to the fact that the national regulations concerning radiation safety and protection corresponded very well. The two countries also have the same kind of specialist training in dentomaxillofacial radiology.

The knowledge of how cone-beam computed tomography was used in dental practices is very important to survey, since radiation dose to the patient could vary a lot for the same kind of radiographic examination. The need for education and training was explicit. The whole dental team should be involved. Thus, it is essential to establish quality assurance protocols with defined responsibilities in the team in order to maintain high diagnostic accuracy for all examinations when using cone-beam computed tomography for patient examinations.

\section{ACKNOWLEDGMENTS AND DISCLOSURE STATEMENTS}

The authors report no conflicts of interest related to this study.

\section{REFERENCES}

1. European Commission. Radiation Protection $\mathrm{N}^{\circ} 172$ cone beam CT for dental and maxillofacial radiology. EvidenceBased Guidelines. Directorate-General for Energy; Directorate D - Nuclear Energy; Unit D4 - Radiation Protection; 2012. [URL: http://www.sedentexct.eu]

2. Holroyd JR, Walker A. HPA-RPD-065: recommendations for the design of X-ray facilities and the quality assurance of dental cone beam CT (computed tomography) systems. Health Protection Agency; Centre for Radiation; Chemical and Environmental Hazards; Radiation Protection Division; Chilton, Didcot, Oxfordshire, England; 2010. [URL: https://www.gov.uk]

3. Haagensen KM. Nordic statistical yearbook 2014. Copenhagen: Nordisk Ministerråd; 2014. p. 157. [doi: 10.6027/Nord2014-001]

4. Nordic dentistry in numbers. Sveriges Tandläkarförbund. Stockholm; 2015 Jan. [URL: http://www.tandlakarforbundet.se]

5. Nihtilä A. A Nordic project of quality indicators for oral health care. National Institute for Health and Welfare, Report 32/2010. Helsinki; 2010. [URL: http://www.julkari.fi]

6. Hol C, Hellén-Halme K, Torgersen G, Nilsson M, Møystad A. How do dentists use CBCT in dental clinics? A Norwegian nationwide survey. Acta Odontol Scand. 2015 Apr;73(3):195-201. [Medline: 25415368] [doi: 10.3109/00016357.2014.979866]

7. Dölekoğlu S, Fişekçioğlu E, İlgüy M, İlgüy D. The usage of digital radiography and cone beam computed tomography among Turkish dentists. Dentomaxillofac Radiol. 2011 Sep;40(6):379-84. [Medline: 2183197] [PMC free article: $\underline{3520338]}$ [doi: $10.1259 / \mathrm{dmfr} / 27837552]$

8. Kamburoglu K, Kursun S, Akarslan ZZ. Dental students' knowledge and attitudes towards cone beam computed tomography in Turkey. Dentomaxillofac Radiol. 2011 Oct;40(7):439-43. [Medline: 21960402] [PMC free article: 3528136$]$ [doi: $10.1259 / \mathrm{dmfr} / 21915689]$

9. Wenzel A, Møystad A. Experience of Norwegian general dental practitioners with solid state and storage phosphor detectors. Dentomaxillofac Radiol. 2001 Jul;30(4):203-8. [Medline: 11681481] [doi: 10.1038/sj.dmfr.4600613]

10. Berkhout WE, Sanderink GC, Van der Stelt PF. Does digital radiography increase the number of intraoral radiographs? A questionnaire study of Dutch dental practices. Dentomaxillofac Radiol. 2003 Mar;32(2):124-7. [Medline: 12775667] [doi: $10.1259 / \mathrm{dmfr} / 97410196$ ] 
11. Hellén-Halme K, Rohlin M, Petersson A. Dental digital radiography: a survey of quality aspects. Swed Dent J. 2005;29(2):81-7. [Medline: 16035351]

12. Bontempi M, Bettuzzi M, Casali F, Pasini A, Rossi A, Ariu M. Relevance of head motion in dental cone-beam CT scanner images depending on patient positioning. Int J CARS 2008; 3:249-55. [doi: 10.1007/s11548-008-0157-1]

13. Horner K, Islam M, Flygare L, Tsiklakis K, Whaites E. Basic principles for use of dental cone beam computed tomography: consensus guidelines of the European Academy of Dental and Maxillofacial Radiology. Dentomaxillofac Radiol. 2009 May;38(4):187-95. [Medline: 19372107] [doi: 10.1259/dmfr/74941012]

14. Lorenzoni DC, Bolognese AM, Garib DG, Guedes FR, Sant'anna EF. Cone-beam computed tomography and radiographs in dentistry: aspects related to radiation dose. Int J Dent. 2012;2012:813768. [Medline: 22548064] [PMC free article: $\underline{3324904]}$ [doi: $10.1155 / 2012 / 813768$ ]

15. Bornstein MM, Scarfe WC, Vaughn VM, Jacobs R. Cone beam computed tomography in implant dentistry: a systematic review focusing on guidelines, indications, and radiation dose risks. Int J Oral Maxillofac Implants. 2014;29 Suppl:55-77. [Medline: 24660190] [doi: 10.11607/jomi.2014suppl.g1.4]

16. Brown J, Jacobs R, Levring Jäghagen E, Lindh C, Baksi G, Schulze D, Schulze R; European Academy of DentoMaxilloFacial Radiology. Basic training requirements for the use of dental CBCT by dentists: a position paper prepared by the European Academy of DentoMaxilloFacial Radiology. Dentomaxillofac Radiol. 2014;43(1):20130291. [Medline: 24132023] [PMC free article: 3887486 ] [doi: 10.1259/dmfr.20130291]

17. Ludlow JB, Ivanovic M. Comparative dosimetry of dental CBCT devices and 64-slice CT for oral and maxillofacial radiology. Oral Surg Oral Med Oral Pathol Oral Radiol Endod. 2008 Jul;106(1):106-14. [Medline: 18504152] [doi: 10.1016/j.tripleo.2008.03.018]

18. Liang X, Jacobs R, Hassan B, Li L, Pauwels R, Corpas L, Souza PC, Martens W, Shahbazian M, Alonso A, Lambrichts I. A comparative evaluation of Cone Beam Computed Tomography (CBCT) and Multi-Slice CT (MSCT) Part I. On subjective image quality. Eur J Radiol. 2010 Aug;75(2):265-9. [Medline: 19410409] [doi: 10.1016/j.ejrad.2009.03.042]

19. Nemtoi A, Czink C, Haba D, Gahleitner A. Cone beam CT: a current overview of devices. Dentomaxillofac Radiol. 2013;42(8):20120443. [Medline: 23818529] [PMC free article: 3922261] [doi: 10.1259/dmfr.20120443]

20. Pradhan AS, Kim JL, Lee JI. On the use of “effective dose” (E) in medical exposures. J Med Phys. 2012 Apr;37(2):63-5. [Medline: 22557794] [PMC free article: 3339144] [doi: 10.4103/0971-6203.94739]

21. McCollough CH, Christner JA, Kofler JM. How effective is effective dose as a predictor of radiation risk? AJR Am J Roentgenol. 2010 Apr;194(4):890-6. Erratum in: AJR Am J Roentgenol. 2010 May;194(5):1404. [Medline: 20308487] [doi: 10.2214/AJR.09.4179]

22. Martin CJ. The application of effective dose to medical exposures. Radiat Prot Dosimetry. 2008;128(1):1-4. [Medline: 17951608] [doi: 10.1093/rpd/ncm425]

23. Martin CJ. Effective dose: how should it be applied to medical exposures? Br J Radiol. 2007 Aug;80(956):639-47. [Medline: 17646189] [doi: 10.1259/bjr/25922439]

24. Pauwels R, Beinsberger J, Collaert B, Theodorakou C, Rogers J, Walker A, Cockmartin L, Bosmans H, Jacobs R, Bogaerts R, Horner K; SEDENTEXCT Project Consortium. Effective dose range for dental cone beam computed tomography scanners. Eur J Radiol. 2012 Feb;81(2):267-71. [Medline: 21196094] [doi: 10.1016/j.ejrad.2012.05.028]

\section{To cite this article:}

Strindberg JE, Hol C, Torgersen G, Møystad A, Nilsson M, Näsström K, Hellén-Halme K.

Comparison of Swedish and Norwegian Use of Cone-Beam Computed Tomography: a Questionnaire Study

J Oral Maxillofac Res 2015;6(4):e2

URL: http://www.ejomr.org/JOMR/archives/2015/4/e2/v6n4e2.pdf

doi: $10.5037 /$ jomr.2015.6402

Copyright (C) Strindberg JE, Hol C, Torgersen G, Møystad A, Nilsson M, Näsström K, Hellén-Halme K. Published in the JOURNAL OF ORAL \& MAXILLOFACIAL RESEARCH (http://www.ejomr.org), 31 December 2015.

This is an open-access article, first published in the JOURNAL OF ORAL \& MAXILLOFACIAL RESEARCH, distributed under the terms of the Creative Commons Attribution-Noncommercial-No Derivative Works 3.0 Unported License, which permits unrestricted non-commercial use, distribution, and reproduction in any medium, provided the original work and is properly cited. The copyright, license information and link to the original publication on (http://www.ejomr.org) must be included. 